\title{
Tumoración intraabdominal secundaria a torsión anexial crónica
}

Intra-abdominal tumour secondary to chronic adnexal torsion

\author{
Daniel Aparicio López ${ }^{1}$ \\ ORCID 0000-0003-4541-1834
}

DOI $10.31837 /$ cir.urug/5.2.13

Recibido: 18 de febrero de 2021

Aceptado: 30 de junio de 2021

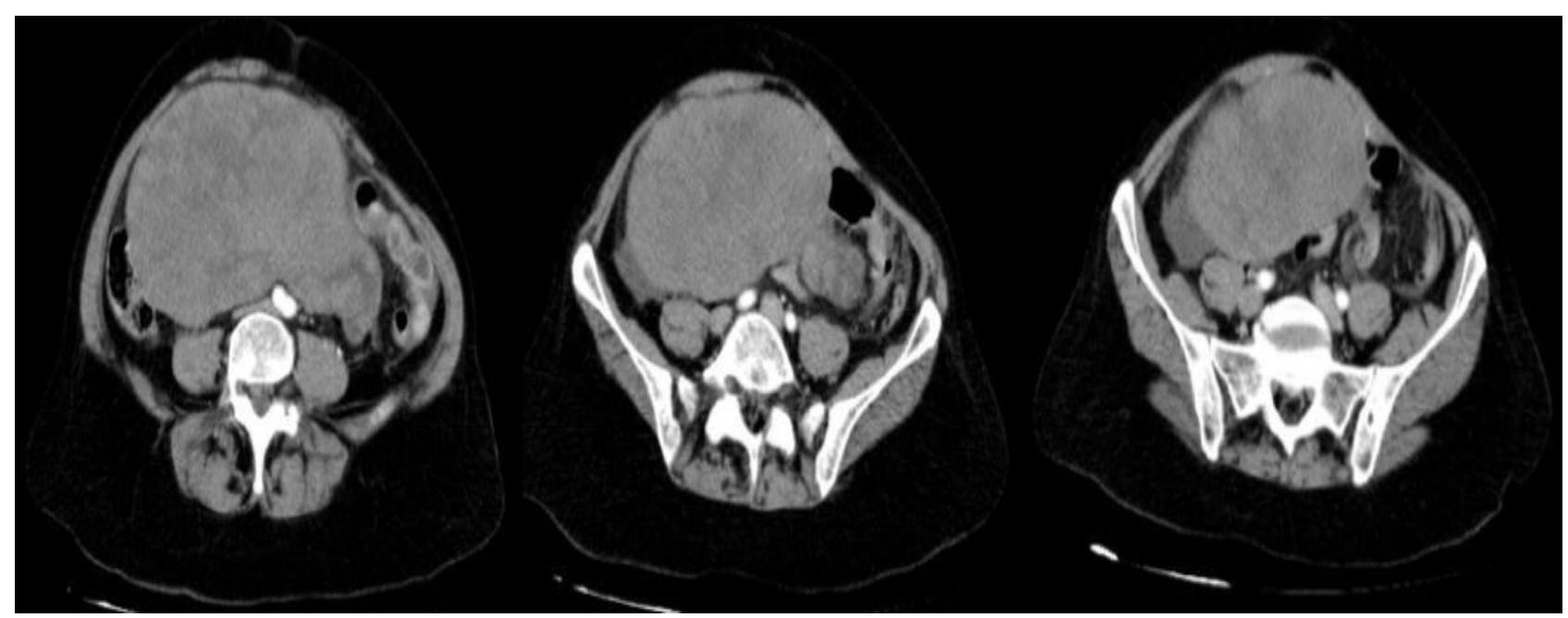

Figura 1.

Mujer de 65 años que consulta por síndrome constitucional y vómitos de 3 meses de evolución. La TC identificó una masa inframesocólica de 25x19x14cm, sólida y heterogénea que desplazaba asas intestinales y vasos mesentéricos (Figura 1).

La biopsia percutánea reveló una tumoración mesenquimal de bajo grado indicándose cirugía. Se evidenció una gran tumoración necro-hemorrágica dependiente del ovario izquierdo y la trompa uterina torsionada realizándose anexectomía (Figura 2). El estudio definitivo certificó una tumoración fusocelular con cambios secundarios a torsión tubárica.

Servicio de Cirugía General y del Aparato Digestivo. Hospital Universitario Miguel Servet

Zaragoza, España.dani_9_93@hotmail.com 


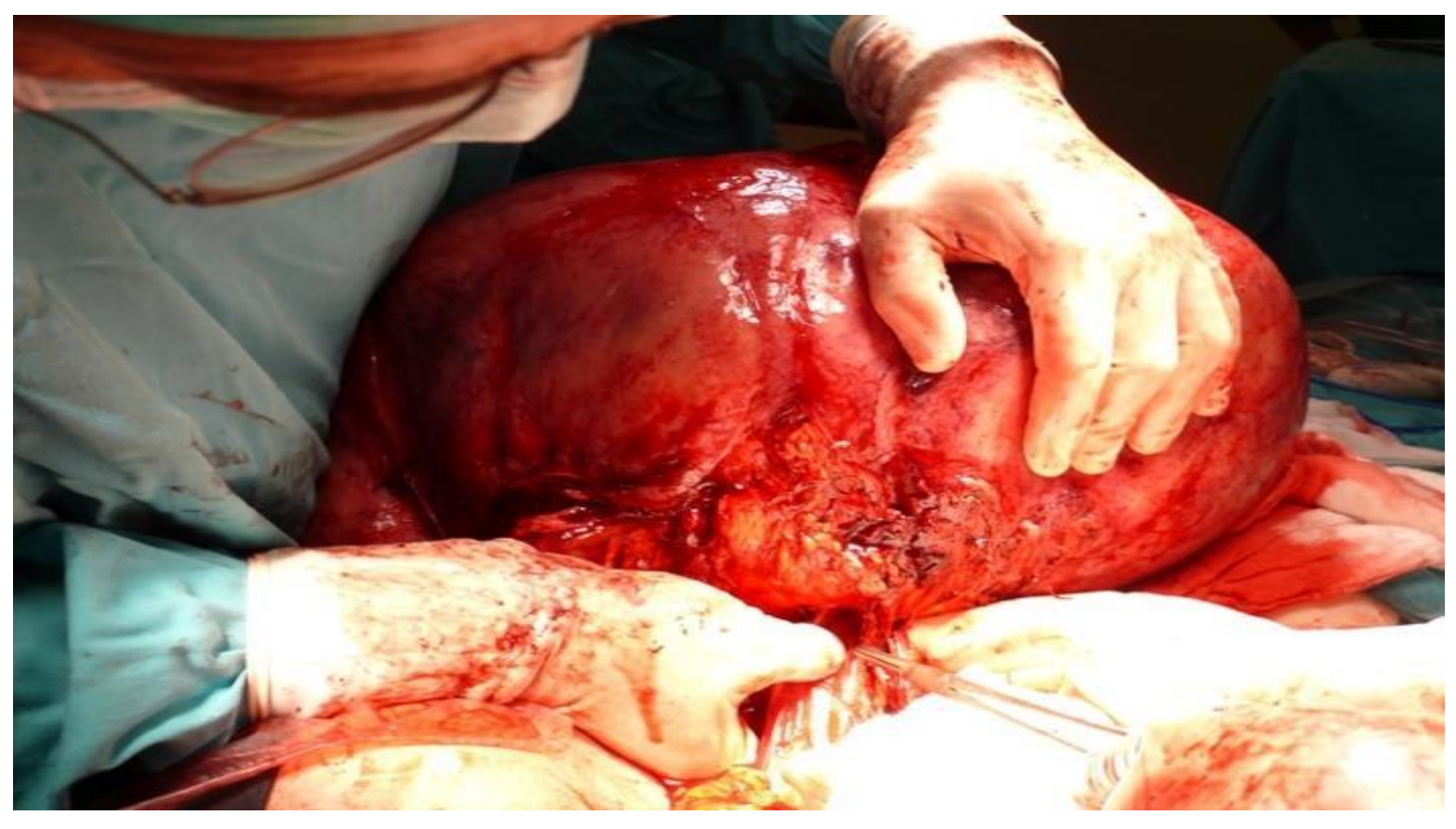

Figura 2 .

La torsión anexial es una emergencia ginecológica poco frecuente causada por la torsión del ovario o la trompa alrededor del ligamento infundibulopélvico. ${ }^{1}$ A menudo se presenta de forma aguda como dolor e irritación peritoneal precisando intervención quirúrgica urgente. ${ }^{2}$ Sin embargo de manera excepcional $(1: 1,5 \text { mill. })^{3}$ su presentación clínica es silente (dolor abdominal vago, vómitos o masa palpable) diagnosticándose tardíamente en pruebas de imagen o estudios anatomopatológicos de piezas quirúrgicas. ${ }^{1}$

Bibliografía

1. Takeda A, Hayashi S, Teranishi Y, Imoto S, Nakamura H. Chronic adnexal torsion: An underrecognized disease entity. Eur J Obstet Gynecol Reprod Biol. 2017;210:45-53. doi: 10.1016/j.ejogrb.2016.12.006.

2. Sasaki KJ, Miller C. Adnexal Torsion: Review of the Literature. J Minim Invasive Gynecol 2014;21(2):196-202. doi: 10.1016/j.jmig.2013.09.010.

3. Phillips K, Fino M, Kump L, Berkeley A. Chronic isolated fallopian tube torsion. Fertil Steril. 2009;92(1):394.e1-394.e3. doi: 10.1016/j.fertnstert.2009.01.152. 